\title{
On ve-degree atom-bond connectivity, sum- connectivity, geometric-arithmetic and harmonic indices of copper oxide
}

\author{
Murat Cancan $^{\mathrm{a}}{ }_{\mid \text {Süleyman Ediz }}^{\mathrm{a}, *}$ \\ aFaculty of Education, Van Yüzüncü Yll \\ University, Van, Turkey \\ ${ }^{b}$ Department of Applied Mathematics, Iran \\ University of Science and Technology, \\ Narmak, 16844, Tehran, Iran
}

|Mohammad Reza Farahanib

Topological indices are important tools to modeling chemical properties of molecules. ve-degree based atom-bond connectivity, sum-connectivity, geometric-arithmetic, and harmonic indices are defined as their corresponding classical degree based counterparts recently in chemical graph theory. In this study we investigate ve-degree atom-bond connectivity, sum-connectivity, geometric-arithmetic, and harmonic topological properties of copper oxide. We calculate exact values of these novel topological indices for copper oxide and give closed formulas.

\section{KEYWORDS}

Ve-degree atom-bond connectivity index; ve-degree sumconnectivity index; ve-degree geometric arithmetic index; vedegree harmonic index.

\author{
*Corresponding Author: \\ Süleyman Ediz \\ Email: suleymanediz@yyu.edu.tr \\ Tel.: +904322251701
}

proposed to be measures of branching of the carbon-atom skeleton [8]. Very recently Chellali et al have published very seminal study about the novel two degree concepts: ve-degrees and ev-degrees in graph theory [6]. The authors defined these novel degree concepts in relation to the vertex-edge domination and the edge-vertex domination parameters [10-12]. The ev-degree and vedegree topological indices have been defined and their basic mathematical properties have been investigated [13-15]. It was showed that, ve-degree sum-connectivity index of octane isomers provides the highest value of correlation coefficient of the property of acentric factor than other well-known topological indices such as Zagreb, Randic, atom-bond connectivity, sum-connectivity indices [13].

The copper oxide/cupric oxide is an inorganic chemical compound $\mathrm{CuO}$. It is an essential mineral found in plants and animals. 
Copper has enormous applications in medical instruments, drugs, as a heat conductor and many others. In Figure 1, the copper hydroxide is depicted and when hydrogen atoms are deleted from $\mathrm{Cu}(\mathrm{OH})_{2}$ then the resultant graph is depicted in Figure 2.

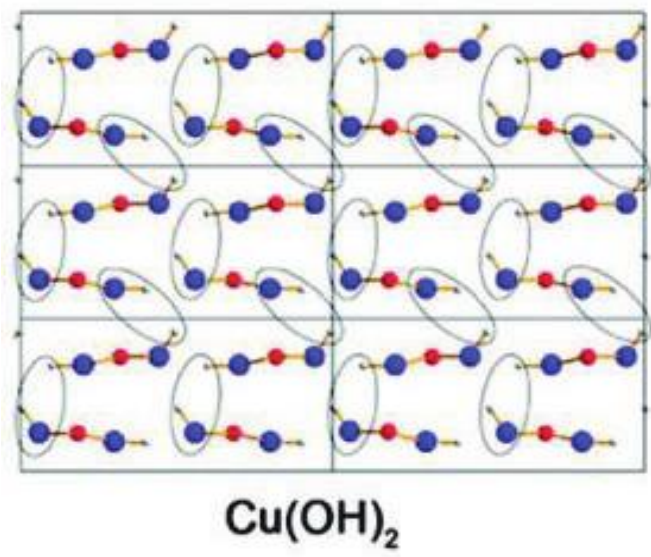

\section{i) $\mathrm{Cu}(\mathrm{OH})_{2} \rightarrow \mathrm{CuO}+\mathrm{H}_{2} \mathrm{O}$}

FIGURE $12 \mathrm{D}$ representation of $\mathrm{Cu}(\mathrm{OH})_{2}$

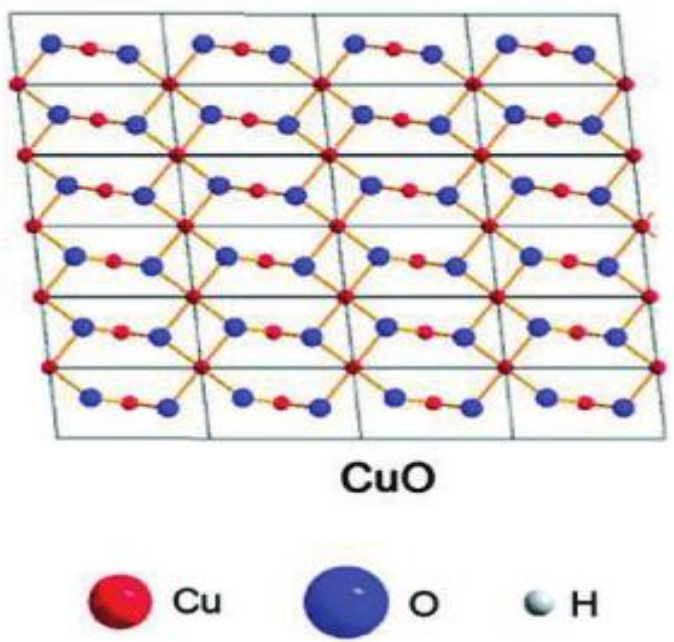

FIGURE 2 2D representation of $\mathrm{CuO}$

The 3D graph of copper oxide $\mathrm{CuO}$ is depicted in Figure 3.

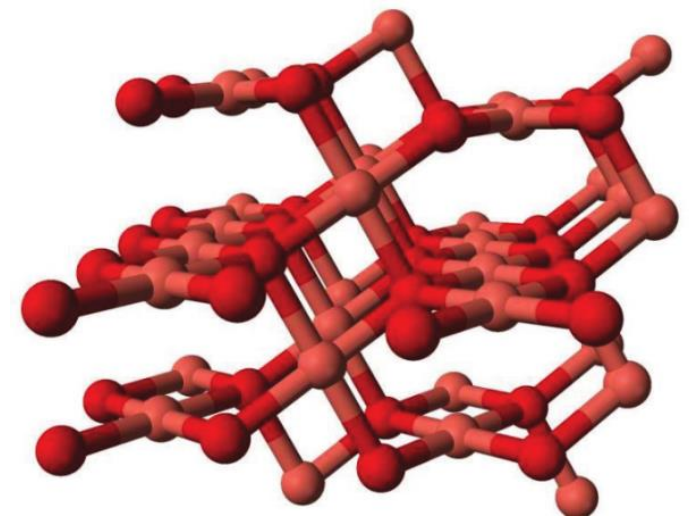

FIGURE 3 3D representation of $\mathrm{CuO}$

The $\mathrm{ABC}, \mathrm{GA}, \mathrm{ABC} 4$, GA 5 , general Randic index and Zagreb index for copper oxide $\mathrm{CuO}$ were calculated $[16,17]$.

\section{Preliminaries}

We consider only connected and simple graphs throughout this work. Let $G$ be a graph with the vertex set $V(G)$, the edge set $E(G)$ and $v \in V(G)$. The degree of a vertex $v \in V(G)$, $\operatorname{deg}(v)$, equals the number of edges incident to $v$ that is the cardinality of the set $N(v)=\{u \mid u v \in E(G)\}$.

Definition 1. Let $G$ be a connected graph and $v \in V(G)$. The ve-degree $\operatorname{deg}_{v e}(v)$, equals the number of different edges that incident to any vertex from the closed (or open) neighborhood of $v$. vertex from the closed (or open) neighborhood of $\mathrm{v}$.

In order to calculate the ve-degrees of the vertices of $\mathrm{CuO}$ we give the edge partition of its vertices with respect to classical degrees in Table 1.

TABLE 1 The degrees of the end vertices of edges for $\mathrm{CuO}$

\begin{tabular}{cc}
\hline $\boldsymbol{d d e g}(\mathbf{u}), \operatorname{deg}(\mathbf{v}))$ & Number of Edges \\
\hline$(2,2)$ & $4(\mathrm{n}+1)$ \\
$(2,3)$ & $2 \mathrm{mn}+2(2 \mathrm{~m}-\mathrm{n})-4$ \\
$(2,4)$ & $4(\mathrm{n}-1)$ \\
$(3,4)$ & $4(\mathrm{mn}-(\mathrm{m}+\mathrm{n})+1)$ \\
\hline
\end{tabular}


From Definition 1 and Table 1, the vedegree partition of copper oxide is given the Table 2 .

TABLE 2 The ve-degrees of the end vertices of edges for $\mathrm{CuO}$

\begin{tabular}{cc}
\hline $\left.\mathbf{d e g}_{\mathbf{v e}}(\mathbf{u}), \mathbf{d e g}_{\mathbf{v e}}(\mathbf{v})\right)$ & Number of Edges \\
\hline$(4,4)$ & 4 \\
$(4,5)$ & 4 \\
$(4,6)$ & $4(\mathrm{n}-1)$ \\
$(5,6)$ & 4 \\
$(6,6)$ & $6 \mathrm{~m}-10$ \\
$(6,10)$ & $2(\mathrm{mn}-(\mathrm{m}-\mathrm{n})-1)$ \\
$(10,10)$ & $4(\mathrm{n}-1)$ \\
$(10,12)$ & $4(\mathrm{mn}-(\mathrm{m}+2 \mathrm{n})+2)$ \\
\hline
\end{tabular}

Definition 2 (ve-degree atom-bond connectivity (ve-ABC) index) Let $G$ be a connected graph and $e=u v$ ? $E(G)$. The vedegree atom-bond connectivity index of the graph $G$ defined as;

$A B C^{v e}(G)=\sum_{u v \in E(G)} \sqrt{\frac{\operatorname{deg}_{v e} u+\operatorname{deg}_{v e} v-2}{\operatorname{deg}_{v e} u d e g_{v e} v}}$

Definition 3 (ve-degree geometricarithmetic (ve-GA) index) Let $G$ be a connected graph and $v$ ? $V(G)$. Ve-degree geometric-arithmetic index of the graph $G$ defined as;

$G A^{v e}(G)=\sum_{u v \in E(G)} \frac{2 \sqrt{\operatorname{deg}_{v e} u d e g_{v e} v}}{\operatorname{deg}_{v e} u+\operatorname{deg}_{v e} v}$

Definition 4 (ve-degree harmonic (ve-H) index) Let $G$ be a connected graph and $u v$ ? $E(G)$. Ve-degree harmonic index of the graph $G$ defined as;

$H^{v e}(G)=\sum_{u v \in E(G)} \frac{2}{\operatorname{deg}_{v e} u+\operatorname{deg}_{v e} v}$

Definition 5 (ve-degree sum-connectivity (ve- $\chi$ ) index) Let $G$ be a connected graph and $u v$ ? $E(G)$. Ve-degree sum-connectivity index of the graph $G$ defined as;

$\chi^{v e}(G)=\sum_{u v \in E(G)}\left(\operatorname{deg}_{v e} u+\operatorname{deg}_{v e} v\right)^{-1 / 2}$

\section{Results}

In this section we compute the ve-degree topological indices for copper oxide.

Theorem 1. Let $\mathrm{G}$ be a connected graph of copper oxide and $u v \in E(G)$. The ve-degree harmonic index of the graph $\mathrm{G}$ is;
$H^{v e}(G)$

$=\frac{17}{9}+\frac{6 n-6}{5}+\frac{3 m-5}{3}$

$+\frac{m n-m+n-1}{4}$

$+\frac{4 m n-4 m-8 n+16}{11}$

Proof. From the Table 2 and Equation 3,

$$
H^{v e}(G)=\sum_{u v \in E(G)} \frac{2}{\operatorname{deg}_{v e} u+\operatorname{deg}_{v e} v}
$$

$=\frac{8}{4+4}+\frac{8}{4+5}+\frac{8(n-1)}{4+6}+\frac{8}{5+6}$

$+\frac{12 m-20}{6+6}+\frac{4 m n-4 m+4 n-4}{6+10}$

$+\frac{8(n-1)}{10+10}$

$+\frac{8 m n-8 m-16 n+16}{10+12}$

$=\frac{17}{9}+\frac{4 n-4}{5}+\frac{8}{11}+\frac{3 m-5}{3}$

$+\frac{m n-m+n-1}{4}+\frac{2 n-2}{5}$

$+\frac{4 m n-4 m-8 n+16}{11}$

$=\frac{17}{9}+\frac{6 n-6}{5}+\frac{3 m-5}{3}+\frac{m n-m+n-1}{4}$

$+\frac{4 m n-4 m-8 n+16}{11}$

Theorem 2. Let $\mathrm{G}$ be a connected graph of copper oxide and uv $\in \mathrm{E}(\mathrm{G})$. The ve-degree sum-connectivity index of the graph $\mathrm{G}$ is;

$\chi^{v e}(G)$

$=\frac{2}{\sqrt{2}}+\frac{4}{3}+\frac{4 n-4}{\sqrt{10}}+\frac{4}{\sqrt{11}}+\frac{3 m-5}{\sqrt{3}}$

$+\frac{m n-m+n-1}{2}+\frac{2 n-2}{\sqrt{5}}$

$+\frac{4 m n-4 m-8 n+8}{\sqrt{22}}$

Proof. From the Table 2 and Equation 4;

$\chi^{v e}(G)=\sum_{u v \in E(G)}\left(\operatorname{deg}_{v e} u+\operatorname{deg}_{v e} v\right)^{-1 / 2}$

$=\frac{4}{\sqrt{4+4}}+\frac{4}{\sqrt{4+5}}+\frac{4(n-1)}{\sqrt{4+6}}+\frac{4}{\sqrt{5+6}}$

$+\frac{6 m-10}{\sqrt{6+6}}+\frac{2 m n-2 m+2 n-2}{\sqrt{6+10}}$

$+\frac{4(n-1)}{\sqrt{10+10}}$

$+\frac{4 m n-4 m-8 n+8}{\sqrt{10+12}}$ 


$$
=\frac{2}{\sqrt{2}}+\frac{4}{3}+\frac{4 n-4}{\sqrt{10}}+\frac{4}{\sqrt{11}}+\frac{3 m-5}{\sqrt{3}}+
$$

$\frac{m n-m+n-1}{2}+\frac{2 n-2}{\sqrt{5}}+$

$\frac{4 m n-4 m-8 n+8}{\sqrt{22}}$

Theorem 3. Let $\mathrm{G}$ be a connected graph of copper oxide and $u v \in E(G)$. The ve-degree geometric-arithmetic index of the graph $\mathrm{G}$ is; $G A^{\text {ve }}(G)$

$$
\begin{aligned}
& =4+\frac{16 \sqrt{5}}{9}+\frac{8(n-1) \sqrt{6}}{5}+\frac{8 \sqrt{30}}{11} \\
& +\frac{6 m-10}{3}+\frac{(m n-m+n-1) \sqrt{15}}{2} \\
& +\frac{4(n-1)}{5} \\
& +\frac{(8 m n-8 m-16 n+16) \sqrt{30}}{11}
\end{aligned}
$$

Proof. From the Table 2 and Equation 2;

$$
\begin{aligned}
& G A^{v e}(G)=\sum_{u v \in E(G)} \frac{2 \sqrt{\operatorname{deg}_{v e} u d e g_{v e} v}}{\operatorname{deg}_{v e} u+\operatorname{deg}_{v e} v} \\
& =\frac{8 \sqrt{4 x 4}}{4+4}+\frac{8 \sqrt{4 x 5}}{4+5}+\frac{8(n-1) \sqrt{4 x 6}}{4+6}+\frac{8 \sqrt{5 x 6}}{5+6} \\
& +\frac{(12 m-20) \sqrt{6 x 6}}{6+6} \\
& +\frac{(4 m n-4 m+4 n-4) \sqrt{6 x 10}}{6+10} \\
& +\frac{8(n-1) \sqrt{6 x 10}}{6+10} \\
& +\frac{(8 m n-8 m-16 n+16) \sqrt{10 x 12}}{10+12} \\
& =\frac{4+\frac{16 \sqrt{5}}{9}+\frac{8(n-1) \sqrt{6}}{5}+\frac{8 \sqrt{30}}{11}}{2} \\
& +\frac{6 m-10}{3}+\frac{(m n-m+n-1) \sqrt{15}}{11} \\
& +\frac{4(n-1)}{5} \\
& +\frac{(8 m n-8 m-16 n+16) \sqrt{30}}{11}
\end{aligned}
$$

Theorem 4. Let $\mathrm{G}$ be a connected graph of copper oxide and $u v \in E(G)$. The ve-degree atom-bond connectivity index of the graph $G$ is

$$
\begin{aligned}
& A B C^{v e}(G)=\frac{2 \sqrt{5}}{\sqrt{2}}+\frac{2 \sqrt{7}}{\sqrt{5}}+\frac{4(n-1) \sqrt{2}}{\sqrt{6}}+\frac{12}{\sqrt{30}} \\
& +\frac{(3 m-5) \sqrt{10}}{3}+\frac{(m n-m+n-1) \sqrt{10}}{\sqrt{15}} \\
& +\frac{(3 n-1) \sqrt{2}}{5}+\frac{(4 m n-4 m-8 n+8)}{\sqrt{6}}
\end{aligned}
$$

Proof. From the Table 2 and Equation 1, $A B C^{\text {ve }}(G)$

$$
\begin{aligned}
& =\sum_{u v \in E(G)} \sqrt{\frac{\operatorname{deg}_{v e} u+\operatorname{deg}_{v e} v-2}{\operatorname{deg}_{v e} u d e g_{v e} v}} \\
& =\frac{4 \sqrt{4+4-2}}{\sqrt{4 x 4}}+\frac{4 \sqrt{4+5-2}}{\sqrt{4 x 5}} \\
& +\frac{4(n-1) \sqrt{4+6-2}}{\sqrt{4 x 6}}+\frac{4 \sqrt{5+6-2}}{\sqrt{5 x 6}} \\
& +\frac{(6 m-10) \sqrt{6+6-2}}{\sqrt{6 x 6}} \\
& +\frac{(2 m n-2 m+2 n-2) \sqrt{6+10-2}}{\sqrt{6 x 10}} \\
& +\frac{4(n-1) \sqrt{10+10-2}}{\sqrt{10 x 10}} \\
& +\frac{(4 m n-4 m-8 n+8) \sqrt{10+12-2}}{\sqrt{10 x 12}} \\
& =\frac{2 \sqrt{5}}{\sqrt{2}}+\frac{2 \sqrt{7}}{\sqrt{5}}+\frac{4(n-1) \sqrt{2}}{\sqrt{6}}+\frac{12}{\sqrt{30}} \\
& +\frac{(3 m-5) \sqrt{10}}{3}+\frac{(m n-m+n-1) \sqrt{10}}{\sqrt{15}} \\
& +\frac{(3 n-1) \sqrt{2}}{5}+\frac{(4 m n-4 m-8 n+8)}{\sqrt{6}}
\end{aligned}
$$

\section{Conclusion}

In this research study, we computed the vedegree atom-bond connectivity, ve-degree sum-connectivity, ve-degree geometricarithmetic and ve-degree harmonic indices of copper oxide. The closed formulas are as follows:

$$
\begin{aligned}
& H^{v e}(G) \\
& =\frac{17}{9}+\frac{6 n-6}{5}+\frac{3 m-5}{3}+\frac{m n-m+n-1}{4} \\
& +\frac{4 m n-4 m-8 n+16}{11} \\
& \chi^{v e}(G) \\
& =\frac{2}{\sqrt{2}}+\frac{4}{3}+\frac{4 n-4}{\sqrt{10}}+\frac{4}{\sqrt{11}}+\frac{3 m-5}{\sqrt{3}} \\
& +\frac{m n-m+n-1}{2}+\frac{2 n-2}{\sqrt{5}} \\
& +\frac{4 m n-4 m-8 n+8}{\sqrt{22}}
\end{aligned}
$$




$$
\begin{aligned}
& G A^{v e}(G) \\
& =4+\frac{16 \sqrt{5}}{9}+\frac{8(n-1) \sqrt{6}}{5}+\frac{8 \sqrt{30}}{11} \\
& +\frac{6 m-10}{3}+\frac{(m n-m+n-1) \sqrt{15}}{2} \\
& +\frac{4(n-1)}{5}+\frac{(8 m n-8 m-16 n+16) \sqrt{30}}{11} \\
& A B C^{v e}(G) \\
& =\frac{2 \sqrt{5}}{\sqrt{2}}+\frac{2 \sqrt{7}}{\sqrt{5}}+\frac{4(n-1) \sqrt{2}}{\sqrt{6}}+\frac{12}{\sqrt{30}} \\
& +\frac{(3 m-5) \sqrt{10}}{3} \\
& +\frac{(m n-m+n-1) \sqrt{10}}{\sqrt{15}} \\
& +\frac{(3 n-1) \sqrt{2}}{5}+\frac{(4 m n-4 m-8 n+8)}{\sqrt{6}}
\end{aligned}
$$

Computation of the ve-degree topological indices of other molecules and the mathematical properties of these novel indices and ve-degree and ev-degree based topological indices of other chemical compounds are interested problems for further studies.

\section{Acknowledgements}

The authors are thankful to the reviewers for their valuable comments and suggestions which improved the presentation of the paper.

\section{Orcid:}

Murat Cancan: https://orcid.org/0000-00028606-2274

Süleyman Ediz: https://orcid.org/0000-00030625-3634

Mohammad

Reza

Farahani:

https://orcid.org/0000-0003-2969-4280

\section{References}

[1] E.G.A. Gomaa, M.A. Berghout, M.R. Moustafa, F.M. El Taweel, H.M. Farid, Prog. Chem. Biochem. Res., 2018, 1, 19-28.

[2] M. Nabati, V. Bodaghi-Namileh, S. Sarshar, Prog. Chem. Biochem. Res., 2019, 2, 108-119.
[3] M.E. Khan, A.S. Adeiza, T.A. Tor-Anyiin and A. Alexander, Prog. Chem. Biochem. Res., 2019, 2, 68-73.

[4] H. Wiener, J. Am. Chem. Soc., 1947, 69, 1720.

[5] J. R. Platt, J. Chem. Phys., 1947, 15, 419-420. [6] I. Gutman, Bull. Cl. Sci. Math. Nat. Sci. Math., 2014, 39, 39-52.

[7] I. Gutman, N. Trinajstic, Chem. Phys. Lett., 1971, 17, 535-538.

[8] I. Gutman, B. Ruscic, N. Trinajstic, C.F. Wilcox, J. Chem. Phys., 1975, 62, 3399-3405.

[9] M. Chellali, T.W. Haynes, S.T. Hedetniemi, T.M. Lewis, Discrete Mathematics, 2017, 340, 31-38.

[10] J. R. Lewis, Vertex-edge and edge-vertex parameters in graphs (Ph.D. thesis), Clemson University, Clemson, SC, USA, 2007, AAI3274303.

[11] J. Lewis, S.T. Hedetniemi, T.W. Haynes, G. H. Fricke, Util. Math., 2010, 81, 193-213.

[12] R. Boutrig, M. Chellali, T.W. Haynes, S.T. Hedetniemi, Aequationes Math., 2016, 90, 355366.

[13] S. Ediz, Int. J. Computing Science and Mathematics, 2018, 9, 1-12.

[14] S. Ediz, Inernational Journal of Systems Science and Applied Mathematics, 2017, 2, 8792.

[15] B. Şahin, S. Ediz, Iranian Journal of Mathematical Chemistry, 2018, 9, 263-277.

[16] M.R. Farahani, W. Gao, A.Q. Baig, W. Khalid, Maced. J. Chem. Chem. En., 2017, 36, 93-99.

[17] W. Gao, M. Imran, M.K. Siddiqui, M. Naeem, F. Jamil, Qumica Nova, 2018, 41, 874879.

How to cite this article: Murat Cancan*, Süleyman Ediz, Mohammad Reza Farahani. On vedegree atom-bond connectivity, sum-connectivity, geometric-arithmetic and harmonic indices of copper oxide. Eurasian Chemical Communications, 2020, 2(5), 641-645. Link: http://www.echemcom.com/article_104702.html 